\title{
Effective Flange Width of Steel Box Girder Bridge According to British Specifications and Japanese Specifications
}

\author{
Wang Huili ${ }^{1, a}$, Wang $Q i^{2, b}$ and Qin Sifeng ${ }^{3, c}$ \\ ${ }^{1}$ Institute of Bridge Engineering, Dalian University of Technology, Dalian 116023, P.R.China; \\ ${ }^{2}$ Institute of Bridge Engineering, Dalian University of Technology, Dalian 116023, P.R.China; \\ ${ }^{3}$ Research Center for Numerical Tests on Material Failure, Dalian University, Dalian 116622 , \\ P.R.China; \\ âwanghuili@dlut.edu.cn, bwangqi03@mail.dlut.edu.cn,' ${ }^{\text {'q }}$ sifeng@dlu.edu.cn
}

\begin{abstract}
Keywords: Steel box, Shear lag, Effective width
Abstract. The British specifications and Japanese specifications are often referred to calculate effective flange width in order to analyze shear lag effect of steel box girder. However, there are some differences between the two specifications. According to the two specifications ,the effective widthes of a simple supported bridge, a continuous girder bridge with two spans and a continuous girder bridge with three spans are discussed. From the results, we can draw the conclusion that it is pessimistic and simple to calculate effective width of simple support beam according to Japanese specifications. The wide span ratio is the key factor for effective width of box girder bridge in British and Japanese specifications. It is more accurate to calculate the effective width of box girder bridge with British specifications.
\end{abstract}

\section{Introduction}

The construction of a steel box girder bridge is widely used because the structure is light with high torsional rigidity. However, if the box girder plate force analysis is not clear, it can easily cause an accident. In the early 1970s, the Cleddau Bridge in Britain , a continuous steel box girder bridge , collapsed during cantilever construction. In the same year,the Westgate Bridge in Australia, a box girder cable-stayed bridge, collapsed because of box girder flange instability. The key reason was ignoring the box girder shear lag effect. It would lead to deviation of box girder cross-section of deflection and stress. Thus, research of box girder shear lag effect became a hot topic. Reisser first suggested on using energy variation method to determine shear lag[1]. He assumed flange displacement function as a quadratic parabola and got flange stress with principle of minimum potential energy. Based on research of Reisser, Kondo Kazuo got the formulas for calculating effective width of flange under concentrated force and uniformly load[2]. K.R.Moffatt and P.J.Dowling got the box beam shear lag of practical charts with finite element method[3] The chats were adopted by British specifications (BS5400)for steel bridge.Jinqiong Guo pointed the key factors of box girder shear lag effect by vibrational method and experiment[4]. Haiyuan Zhang defined shear lag moment based on generalized force on girder section[5].

The shear lag effect is complex so engineers design girder according to specifications. British specifications and Japanese specifications are often referred. However, there are some differences between the two specifications, such as calculation models and the calculation method for shear lag. In this paper, we focus on the differences between British specifications and Japanese specifications about shear lag. The effective width of a continuous girder bridge with two spans would be discussed according to the two specifications.

\section{The shear lag and effective width}

Longitudinal bending moments would cause shear force of thin-walled box girder at the flange and web joint. Because of the shear force, the normal stress of at the upper and lower flange along the 
width direction is distributed uneven. This phenomenon is called the shear lag effect. The shear lag effect is complex and affected with wide span ratio, box girder cross section shape, stiffening rib area and its layout, type of the load, load location, support conditions and so on. Engineers adopt effective width to solve shear lag. The effective width is

$$
b_{e}=\frac{\int \sigma d x}{\bar{\sigma}}
$$

where $\sigma$ is the real stress distributed function, $\bar{\sigma}$ is the nominal stress calculated with elementary beam theory, shown in Fig.1.

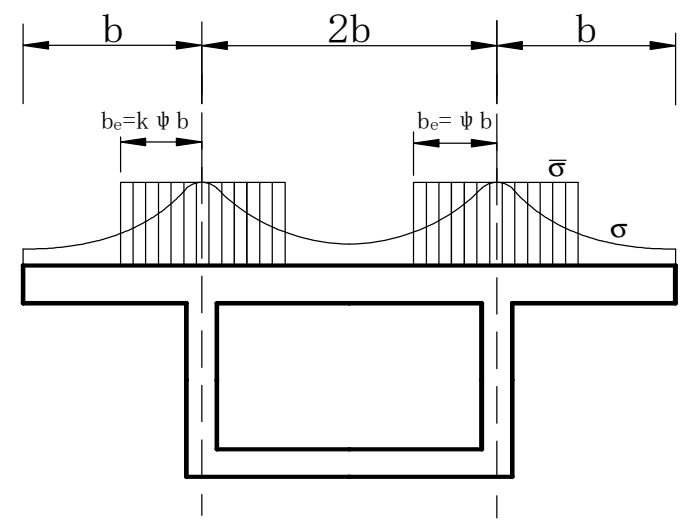

Figure 1 Stress distribution and effective width of box girder

British specifications (BS 5400). K.R. Moffatt and P.J. Dowling calculated the effective width of 15 kinds of rectangular box girder cross section by the finite element method[3]. Referring to their research result, British steel bridge specifications was revised[6]. Two kinds of cross sections were shown in Fig. 2 and Tab.1.

$$
\alpha=\frac{A}{A^{\prime}}
$$

where $A$ is the sectional area of flange stiffeners in width b. $A^{\prime}$ is the sectional area of flange plate in width $b$.

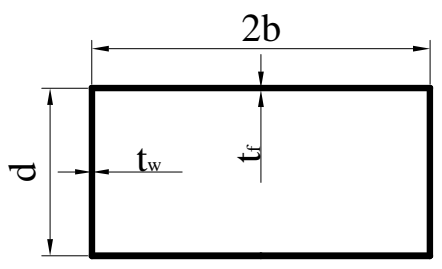

a) $\alpha=0$

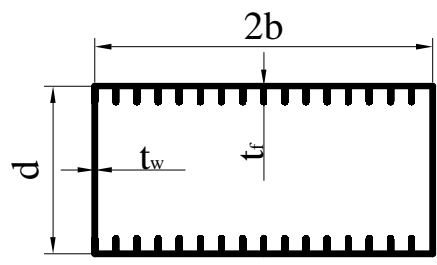

b) $\alpha=1$

Figure 2 Cross section used by K.R.Moffattand P.J.Dowling

Table1 the size of cross section used by K.R.Moffattand P.J.Dowling

\begin{tabular}{cccccc}
\hline Cross section & $\mathrm{b}[\mathrm{ft}]$ & $\mathrm{d}[\mathrm{ft}]$ & $\mathrm{t}_{\mathrm{f}}[\mathrm{ins}]$ & $\mathrm{t}_{\mathrm{w}}[\mathrm{ins}]$ & flange stiffeners \\
\hline a) $\alpha=0$ & 6 & 6 & 1 & 0.5 & - \\
b) $\alpha=1$ & 6 & 6 & 0.5 & 0.5 & $4.5 \mathrm{in} \times 1$ in @9in c/c
\end{tabular}

About shear lag and effective width, the British standard (BS5400) provides as follows. (1) $b_{e}=\varphi b$ for portions between webs

Where $\mathbf{b}$ is half distance between webs.

$\varphi$ is reduction coefficient of effective flange width, which is related to $\alpha$ and $b / l$. The values are provided for a simple supported beam, cantilever beam, mid-span of a continuous beam and side-span of a continuous beam in BS 5400. 
(2) $b_{e}=k \varphi b$ for portions projecting beyond an outer web.

$b$ is the distance from the free edge of the projecting portion to the centre of the outer web, measured along the mid-plane of the flange plate. $k=1-0.5 b / \mathrm{L} . \mathrm{L}$ is the span of a beam between centres of support, or in the case of a cantilever beam, between the support and the free end.

Japanese specifications. Japanese scholars calculated box beam shear lag effect under the uniformly distributed load and concentration load, and then got two reduction factor curves. The reduction factor curve in the Japanese specifications is between the two curves. About shear lag and effective width, the Japanese standard provides as follows[7].the effective width of section at mid-span

$$
\begin{cases}C_{L}=b & \left(\frac{b}{l} \leq 0.05\right) \\ C_{L}=\left[1.1-2\left(\frac{b}{l}\right)\right] b & \left(0.05 \leq \frac{b}{l} \leq 0.3\right) \\ C_{L}=0.15 l & \left(\frac{b}{l} \geq 0.3\right)\end{cases}
$$

where $\mathrm{b}$ is half distance between webs. $l$ is equivalent span.

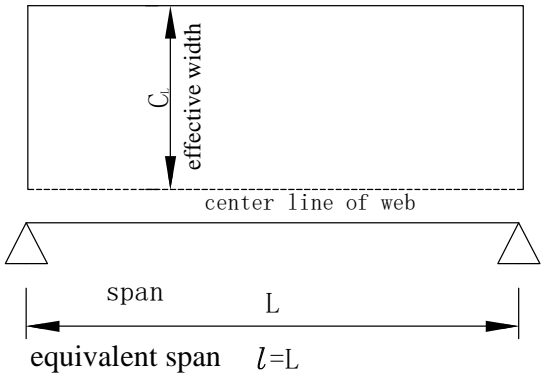

a. simple supported beam $l=0.8 \mathrm{~L} 1 \quad l=0.2(\mathrm{~L} 1+\mathrm{L} 2) \quad l=0.6 \mathrm{~L} 2 \quad l=0.2(\mathrm{~L} 2+\mathrm{L} 3)$

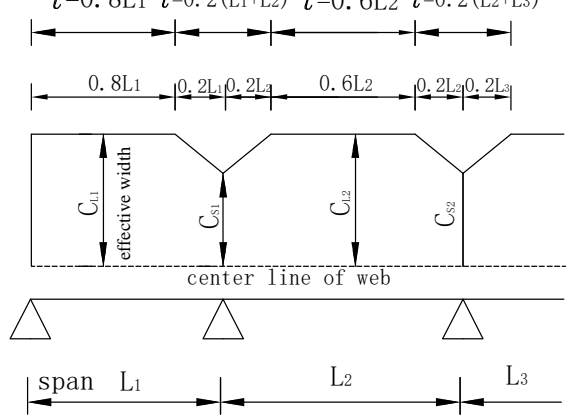

b continuous beam

Figure 3 equivalent span and effective width of section according to Japanese specifications

\section{Comparison between the two specifications}

Effective width $b_{e}$ is calculated by reduction coefficient $\varphi$ both in Japanese specifications and British specifications. The reduction coefficient $\varphi$ in Japanese specifications is related to wide span ratio $b / l$ and section position, while the reduction coefficient $\varphi$ in British specifications is related to wide span ratio $b / l$, sectional area ration of flange stiffeners $\alpha$ and section position.

In Japanese specifications, equivalent span is 0.8 or 0.6 , respectively, multiplied by the side span or middle span. In British specifications, equivalent span is taken as the distance between ascent points at which the bending moment is zero. The results at mid-support and side-support were shown in Fig. 4. 


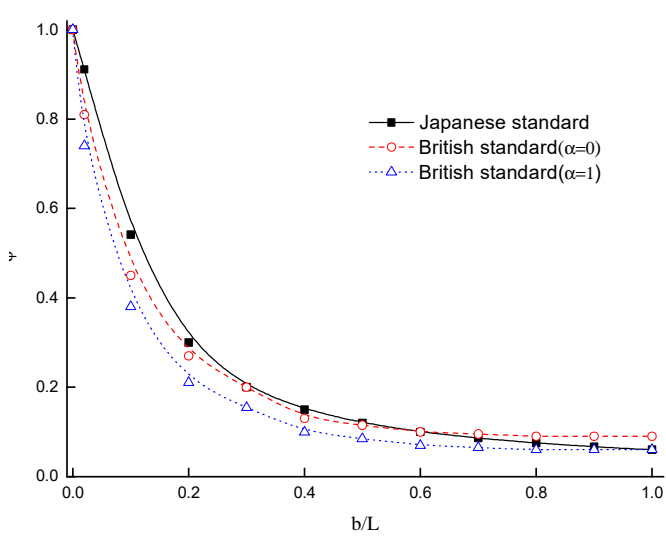

a. Side-support

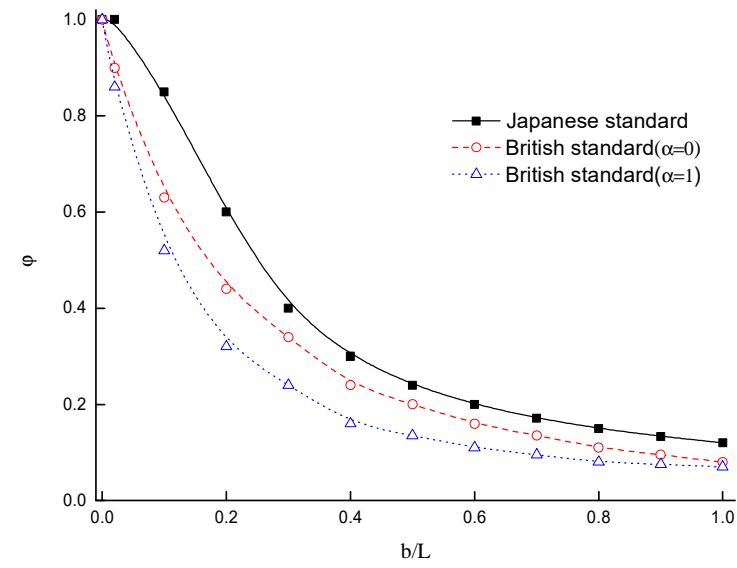

b. mid-support

Figure 4 reduction coefficient continuous beam beam

From the results, we can know that

(1) The results are close at mid-support according to British specifications and Japanese specifications.

(2) For side-support, the reduction coefficient calculated according to British specifications is smaller than Japanese specifications. The difference of reduction coefficient between British specifications and Japanese specifications is more than $50 \%$.

\section{Conclusion}

(1) It is pessimistic and simple to calculate effective width of simple support beam according to Japanese specifications.

(2) For continuous beam support, the reduction coefficient calculated according to British specifications is smaller than Japanese specifications. The reduction coefficient is close at mid-span of continuous beam according to British specifications and Japanese specifications.

(3) The wide span ratio is the key factor for effective width of box girder bridge in British and Japanese specifications. The rib stiffness and shear lag distribution are also influencing factors in British specifications. It is more accurate to calculate the effective width of box girder bridge with British specifications.

\section{Acknowledgements}

This work is supported by the Foundation of Liaoning Provincial Doctoral Scientific research Projects (20170520138), Foundation of Liaoning Provincial Department of Education Projects (L2014027), Foundation of Research Funds for the Central Universities (DUT15QY34).

\section{Reference}

[1] Reissner E: Analysis of shear lag in box beam by principle of minimum potential energy. Quarterly of Applied Mathematics, Vol. 5 (1946), p. 268-278.

[2] Kazuo K, Komatsu. Effective width ofthe steel box girder bridge, Conference Proceeding of Civil Engineering (1962).

[3] K.R.MOFFATT, P.J.DOWLING. Shear lag in steel box girder bridges, Structural Engineering, Vol. 53 (1975), p. 439-448.

[4] Jinqiong G, Zhenzheng F, Xiaodeng L. Analysis of shear lag effect in box girder bridges, China Civil Engineering Journal, Vol. 16 (1983), p. 1-13. 
[5] Yuanhai Z, Xin B, Lixia L. An improved approach for analyzing shear lag effect of box girders, China Civil Engineering Journal. Vol. 45 (2012), p. 153-158.

[6] Steel, concrete and composite bridges -Part 3: Code of practice for design of steel bridges. BS 5400-3 (2000).

[7] Japanese Specifications for Bridge and Road (2012). 